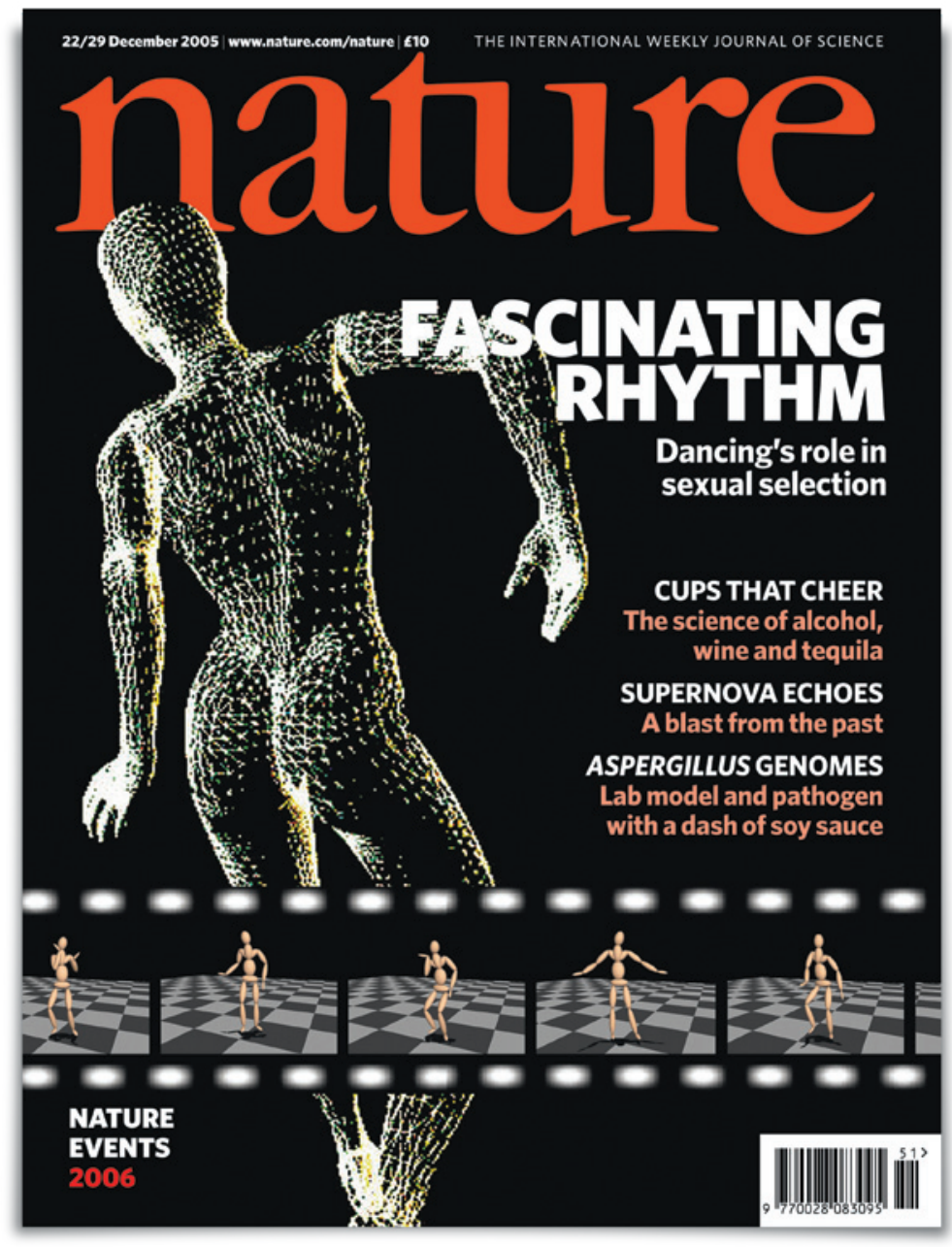

A study featured in Nature in $\mathbf{2 0 0 5}$ has drawn suspicion from university officials and one of its authors.

\title{
SEXUAL SELECTION
}

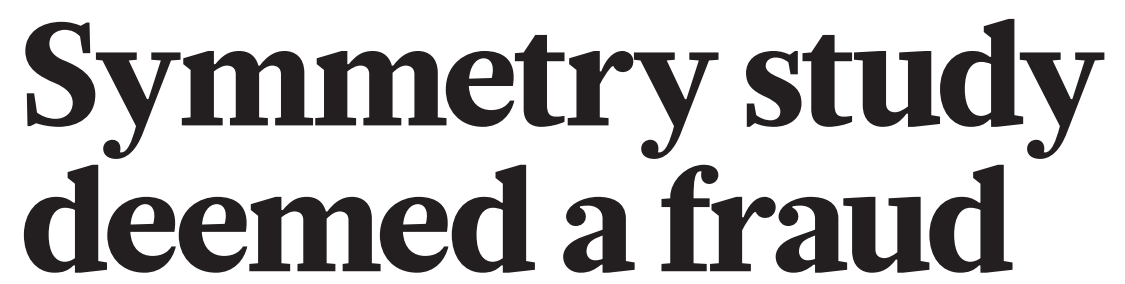

\section{University finds evidence of fakery in Jamaican dance data.}

\section{BY EUGENIE SAMUEL REICH}

$\mathrm{F}$ ew researchers have tried harder than Robert Trivers to retract one of their own papers. In 2005, Trivers, an evolutionary biologist at Rutgers University in New Brunswick, New Jersey, published an attentiongrabbing finding: Jamaican teenagers with a high degree of body symmetry were more likely to be rated 'good dancers' by their peers than were those with less symmetrical bodies. The study, which suggested that dancing is a signal for sexual selection in humans, was featured on the cover of this journal (W. M. Brown et al. Nature 438, 1148-1150; 2005).

But two years later, Trivers began to suspect that the study data had been faked by one of his co-authors, William Brown, a postdoctoral researcher at the time. In seeking a retraction, Trivers self-published The Anatomy of a Fraud, a small book detailing what he saw as evidence of data fabrication. Later, Trivers had a verbal altercation over the matter with a close colleague and was temporarily banned from campus.

An investigation of the case, completed by Rutgers and released publicly last month, now seems to validate Trivers' allegations. Brown disputes the university's finding, but it could help to clear the controversy that has clouded Trivers' reputation as the author of several pioneering papers in the 1970s. For example, Trivers advanced an influential theory of 'reciprocal altruism', in which people behave unselfishly and hope that they will later be rewarded for their good deeds. He also analysed human sexuality in terms of the investments that mothers and fathers each make in child-rearing.

Steven Pinker, a psychologist at Harvard University in Cambridge, Massachusetts, calls the dancing paper "a lark" and "journalist bait" that lacks a firm basis in theory. "It was cute rather than deep," he says. But he describes Trivers' earlier work as "monumental", and says that it would be a travesty if Trivers became known for one controversial study rather than his wider contributions to evolutionary biology. "Trivers is one of the most important thinkers in the history of the biological and social sciences," Pinker says.

\section{SIGNIFICANT MEASURES}

Since the publication in the early 1990s of studies showing that birds and insects tend to seek mates with symmetrical features, biologists have been interested in the possibility that physical symmetry is subject to sexual selection and is correlated with health. In 1996, Trivers began a long-term study of asymmetry in Jamaican children. He measured the degree to which elbow width or finger length, for instance, differed between the right side and the left, and worked to correlate it with fitness traits such as running ability. In 2004, he and Lee Cronk, an anthropologist also at Rutgers, began to study symmetry in relation to dancing. (As early as 1871, Charles Darwin speculated that dancing is a courtship ritual meant to display genetic fitness.)

Trivers, Cronk and their collaborators used motion-capture cameras and reflectors to record the movements of Jamaican teenagers as they danced. The researchers then made animations that recapitulated the dancers' movements but not their appearances. Other teenagers watched the animations and rated the dancing. The 2005 paper reported that good dancing correlated with high levels of physical symmetry - even when symmetry was not evident to the viewer. The finding suggested that good dancing might accurately convey a dancer's genetic fitness to spectators, and helped to establish dance as an area worthy of research for evolutionary biologists and psychologists. "This was a paper we based a lot of our work on because it led the field," says Nick Neave, a psychologist who studies dancing at the University of Northumbria in Newcastle, UK.

Trivers began to have doubts in 2007, when a Rutgers graduate student was unable to replicate some of the paper's findings. On investigation, Trivers found inconsistencies in symmetry measurements between a data set kept by his group and one received from Brown in 2007. "Not only were the values changed, they were not even internally consistent," says Trivers.

In 2008, Trivers sought to retract the paper, but found the editors at Nature reluctant to do 
so. The paper remains unretracted, although a spokeswoman for Nature says that the case is under "active consideration". (Information available to Nature's research-manuscript editors is not generally shared with its reporters.)

In 2009, after Trivers published a book about the dispute, Rutgers convened an investigation in accordance with requirements of the

\US National Science Foundation (NSF), which had spent US $\$ 25,000$ on a grant to Trivers and Cronk to develop the motion-capture technique. Last year, the investigation concluded that there was "clear and convincing" evidence of fabrication by Brown, who it alleged had altered overall asymmetry measures of danc-

ers to support the notion that better dancers were more symmetrical. The report was not published for more than a year, at which point Trivers posted it online. Rutgers has sent a copy to the NSF's inspector-general, who is reviewing it to determine what action, if any, to take. The university officials who oversaw the investigation declined Nature's interview requests.

Brown, now a psychologist at the University of Bedfordshire, UK, denies fabricating the data. He criticizes the Rutgers investigation for comparing his data set with the one from Trivers' group rather than the original hard copies of the source data. Trivers says that the paper records of the asymmetry measurements were reliably entered in his group's database, but Brown says that it is unclear which data set is the original because many versions exist. Brown says that he will not support retracting the paper unless the original data are re-evaluated by an unbiased party and the results are found to be substantially different.

Meanwhile, Trivers

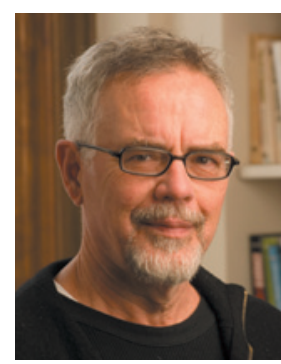
accuses the university of penalizing him for an incident that took place in Cronk's office in March 2012. Trivers says that he said loudly to Cronk, who had disputed Trivers' allegations against Brown: "Well, [the investigation report] supports my position Robert Trivers.

down the line and nothing of what you said, you punk." He says that Rutgers then banned him from campus for nearly five months under the university's anti-violence policy.

Richard Wrangham, an evolutionary biologist at Harvard University, says that Trivers' vehemence is characteristic. "When Bob Trivers gets hold of something intellectually, he is passionate and honest, and this represents that," he says. Wrangham adds that Trivers typically does not have "great political sensitivity". Rutgers says that it cannot comment on personnel matters. Cronk declined an interview request but wrote in an e-mail that, contrary to statements by Trivers and in the investigation report, he had not defended Brown.

As to the paper's claim of a correlation between body symmetry and dancing skill, there might be something to it, says Steven Gangestad, a psychologist at the University of New Mexico in Albuquerque, who says that he reviewed the 2005 paper for Nature. He asked that the authors test the correlation with a more conservative statistical method. When this test robustly reconfirmed the effect, he recommended publication. He says that he has always found the magnitude of the correlation surprisingly strong compared with other symmetry studies. "The sad thing is I think there probably really was an effect," he says, just a much weaker one.

Trivers agrees. He says there is a weak but not very significant effect in the data held by his group. He has no plans to replicate the work on dancing, but his symmetry studies in Jamaica continue and have produced at least ten publications. He has just submitted for publication a study of physical symmetry and running ability that he calls "groundbreaking". "The project is alive and well, and it wasn't sunk by this damn thing," he says. 